\title{
Incidence and risk factors of atrial fibrillation in Asian COPD patients
}

\author{
This article was published in the following Dove Press journal: \\ International Journal of COPD \\ 23 August 2017 \\ Number of times this article has been viewed
}

\author{
Kuang-Ming Liao' \\ Chung-Yu Chen ${ }^{2,3}$ \\ 'Department of Internal Medicine, \\ Chi Mei Medical Center Chiali, Tainan, \\ ${ }^{2}$ Master Program in Clinical Pharmacy, \\ School of Pharmacy, Kaohsiung \\ Medical University, ${ }^{3}$ Department \\ of Pharmacy, Kaohsiung Medical \\ University Hospital, Kaohsiung, Taiwan, \\ Republic of China
}

Objective: To investigate the incidence and risk factors of atrial fibrillation (AF) in Asian chronic obstructive pulmonary disease (COPD) patients.

Patients and methods: We selected a study population older than 40 years with a COPD diagnosis and who had used at least one inhaled bronchodilator medication between 1998 and 2012. The date of the index COPD diagnosis was defined as the index date. We excluded patients with a history of AF, significant mitral valve disease, disorders of the thyroid gland, or ischemic heart disease before the index date. We followed all patients from the index date to the day of AF occurrence, the day of death, or the date of December 31, 2013. The baseline of comorbidities was identified before the index date. Comorbidities included hypertension, diabetes mellitus, end-stage renal disease, congenital heart failure, stroke, peripheral arterial occlusive disease, and malignancy.

Results: We included 6,208 COPD patients and 12,409 patients without COPD. The incidence of AF was higher in COPD patients than in those without COPD. The adjusted hazard ratio (HR) for AF among those with COPD was 2.23 with a $95 \%$ confidence interval (CI) of 1.98-2.51 compared to those without COPD. After multiple analyses, patients with hypertension (HR 1.43 [95\% CI $=1.26-1.62]$ ) or heart failure (HR 2.36 [95\% CI =1.81-3.08]) were found to have a significantly higher incidence of AF than those without these conditions.

Conclusion: It is important for physicians to monitor, prevent, and provide early intervention for $\mathrm{AF}$ in COPD patients with hypertension or heart failure.

Keywords: atrial fibrillation, COPD, incidence

\section{Introduction}

Atrial fibrillation (AF) is a common arrhythmia observed in clinical practice. ${ }^{1}$ AF is also an important risk factor for stroke, and the risk of AF increases with age, rising from $1.5 \%$ at an age of $50-59$ years to $23.5 \%$ at an age of $80-89$ years. ${ }^{2}$ From 1985 to 1999 , hospitalizations for AF increased threefold, and the high prevalence of AF resulted in greater medical expenditures. ${ }^{3}$ Many risk factors for AF exist, including older age, male gender, diabetes mellitus (DM), valvular heart disease, hypertension, myocardial infarction, congestive heart failure (CHF), chronic obstructive pulmonary disease (COPD), obesity, elevated inflammatory markers, and PR-interval prolongation. ${ }^{4}$

AF is commonly observed in COPD patients in clinical practice. A wide variety of factors can cause and trigger AF in COPD patients, ${ }^{5-9}$ such as smoking, oxidative stress, tissue hypoxia, effects of beta agonists, systemic glucocorticoid use, and the chronic inflammatory status in COPD. A previous study used continuous electrocardiography to monitor arrhythmias in patients with COPD and found that the incidence of AF was significantly greater in COPD patients than in patients without COPD. ${ }^{10}$ A retrospective study using the Spanish National Hospital Discharge Database showed that during
Correspondence: Chung-Yu Chen School of Pharmacy, Kaohsiung Medical University, 100 Shih-Chuan I st Road, Sanmin District, Kaohsiung 80708 ,

Taiwan, Republic of China Email jk2975525@hotmail.com 
hospitalization for AF, COPD patients had an increased length of hospital stay and increased hospital mortality. ${ }^{11}$ The Atherosclerosis Risk in Communities (ARIC) cohort study used codes from the International Classification of Diseases to survey the incidence of AF and found that the hazard ratios (HRs) of AF, when comparing the lowest with the highest quartile of forced expiratory volume in 1 second, were 1.37-1.63 for women and 1.49-2.36 for men. ${ }^{12}$ The Malmö Prevention Project also showed that the forced expiratory volume in 1 second was inversely related to the incidence of AF. ${ }^{13}$ There is a paucity of information on AF incidence and risk factors in patients with COPD in most studies, ${ }^{10,14}$ and they lack information regarding Asian populations. The aim of our study was to use a nationwide database to investigate the incidence of AF in Asian COPD patients and explore the independent risk factors for AF in this population.

\section{Patients and methods}

\section{Data source}

This was a population-based retrospective cohort study. We used data from the Longitudinal Health Insurance Database (LHID) 2005 collected from 1997 to 2013. The LHID 2005 contains the original claim data of 1,000,000 beneficiaries enrolled in the year 2005 who were randomly sampled from the 2005 Registry for Beneficiaries of the National Health Insurance Research Database (NHIRD). This database contains claim data regarding patients' ambulatory, inpatient, and outpatient expenditures as well as the details of the orders. The dose, drug type, quantity, and dispensing date of prescription drugs are also contained in the NHIRD. This study was based in part on data from NHIRD, which in this study consisted of de-identified secondary data released to the public for research purposes, and this study was approved by the institutional review board of Kaohsiung Medical University Hospital (KMUH-IRB-EXEMPT(II)-20170003). The current NHIRD, hospital regulations, and guidelines did not indicate a need for informed consent in this retrospective cohort study due to de-identified secondary data. All procedures were in accordance with the ethical standards of the Institutional Research Committee and the directives of the Declaration of Helsinki.

\section{Study population}

We selected a study population older than 40 years with an index COPD diagnosis (International Classification of Diseases-9-Clinical Modification [ICD-9-CM]: 490-492, 496; A-code: A323 and A325) and at least one prescription (over 30 days) of long-acting muscarinic antagonists, long-acting beta-agonists, or long-acting beta-agonists and inhaled corticosteroids, within 90 days after the index date between 1998 and 2012, from the LHID 2005. The date of the index COPD diagnosis was defined as the index date in the study population. We excluded patients with a history of AF (ICD-9-CM code: 427.3), significant mitral valve disease (ICD-9-CM code: 394-396, 424, 746), disorders of the thyroid gland (ICD-9-CM code: 240-246), or ischemic heart disease (ICD-9-CM code: 410-414) before the index date. We matched these patients with patients without COPD based on age, gender, and year of hospital visit at a 1:2 ratio, which constituted the control group. The control group did not have AF, significant mitral valve disease, ischemic heart disease, or disorders of the thyroid gland.

\section{Outcomes and baseline characteristics}

We followed all patients from the index date to the day of AF occurrence, the day of death, the date of December 31, 2013, or until withdrawal from the NHIRD. The baseline of comorbidities was identified from one outpatient diagnosis or one inpatient diagnosis 1 year before the index date. Comorbidities included hypertension (ICD-9-CM: 401-405), DM (ICD-9-CM: 250), hyperlipidemia (ICD-9-CM: 272), endstage renal disease (ESRD; ICD-9-CM: 585.6, 585.5), CHF (ICD-9-CM: 428), stroke (ischemic and hemorrhagic; ICD-9-CM: 430-438), peripheral arterial occlusive disease (PAOD; ICD-9-CM: 443, 440.2-440.9, 4448, 4478, 4479), or malignancy (ICD-9-CM: 140-208). Demographic characteristics were evaluated in patients with or without COPD and included gender, age group (40-49, 50-59, 60-69, and $>70$ years old), and urbanization (level 1 [highest] to 4 [lowest]).

\section{Statistical analysis}

The risk of AF for the COPD and non-COPD groups was examined during a 15-year follow-up. Continuous variables are presented as mean and standard deviation (SD) and compared between the case and control groups with Student's $t$-test. Categorical variables are presented as numbers and percentages, and the differences between cases and controls were compared with the chi-square test. The number of AF events, total follow-up person-years, and incidence of events were calculated in the case and control groups and stratified by gender and comorbidities (patients with any of these diseases, including hypertension, DM, hyperlipidemia, ESRD, CHF, stroke, PAOD, and malignancy). To calculate the risk of $\mathrm{AF}$ between COPD and non-COPD patients during follow-up, the Cox regression hazards model using univariate 
and multivariate analyses was used to assess HRs and 95\% confidence interval (CIs). The multivariable model was adjusted for age groups $(40-49,50-59,60-69$, and $>70$ years old), urbanization (level 1 to 4), gender, and comorbidities (hypertension, DM, hyperlipidemia, ESRD, CHF, stroke, PAOD, malignancy). Furthermore, we assessed the HR of AF between the case and control groups for a variety of different risk factors. Kaplan-Meier curves were used to assess the difference in the cumulative AF incident rate between the case and control groups and the time-to-event curves for the two groups. A $P$-value $<0.05$ was considered to be statistically significant in all statistical analyses. All data processing and statistical analyses were performed using the $\mathrm{SAS}^{\circledR}$ software version 9.4 (SAS Institute Inc., Cary, NC, USA).

\section{Results}

\section{Baseline characteristics}

The baseline characteristics of the population with and without COPD in our study are shown in Table 1 . We included 6,208 patients with COPD and 12,409 patients without COPD;

Table I Demographic characteristics and comorbidities of patients with and without COPD

\begin{tabular}{|c|c|c|c|}
\hline $\begin{array}{l}\text { Characteristics and } \\
\text { comorbidities }\end{array}$ & $\begin{array}{l}\text { Non-COPD } \\
(n=12,409)\end{array}$ & $\begin{array}{l}\text { COPD } \\
(n=6,208)\end{array}$ & $P$-value \\
\hline Age, years (mean \pm SD) & $62.03 \pm 11.46$ & $62.03 \pm 11.44$ & 0.9729 \\
\hline \multicolumn{3}{|c|}{ Age stratification, years, n (\%) } & 1.0000 \\
\hline $40-49$ & $2,182(17.58)$ & I,092 (I7.59) & \\
\hline $50-59$ & $2,917(23.51)$ & $\mathrm{I}, 459(23.50)$ & \\
\hline $60-69$ & $3,747(30.20)$ & I,874 (30.19) & \\
\hline$\geq 70$ & $3,563(28.71)$ & $\mathrm{I}, 783(28.72)$ & \\
\hline Gender, n (\%) & & & 0.9643 \\
\hline Male & $9,353(75.37)$ & 4,681 (75.40) & \\
\hline Female & $3,056(24.63)$ & I,527 (24.60) & \\
\hline Urbanization, ${ }^{a}$ n (\%) & & & 0.0001 \\
\hline I (highest) & $3,301(26.60)$ & I,477 (23.79) & \\
\hline 2 & $5,565(44.85)$ & $2,783(44.83)$ & \\
\hline 3 & $2,014(16.23)$ & $1,062(17.11)$ & \\
\hline 4 (lowest) & $1,529(12.32)$ & $886(14.27)$ & \\
\hline \multicolumn{4}{|l|}{ Comorbidities, n (\%) } \\
\hline Hypertension & $3,382(27.25)$ & $2,193(35.33)$ & $<0.0001$ \\
\hline DM & 917 (7.39) & 491 (7.91) & 0.2064 \\
\hline Hyperlipidemia & $1,209(9.74)$ & $746(12.02)$ & $<0.000 \mathrm{I}$ \\
\hline Stroke & $776(6.25)$ & $660(10.63)$ & $<0.0001$ \\
\hline PAOD & $146(1.18)$ & $100(1.61)$ & 0.0144 \\
\hline $\mathrm{CHF}$ & 91 (0.73) & 279 (4.49) & $<0.0001$ \\
\hline Cancer & 717 (5.78) & $550(8.86)$ & $<0.0001$ \\
\hline ESRD & $219(1.76)$ & 191 (3.08) & $<0.0001$ \\
\hline
\end{tabular}

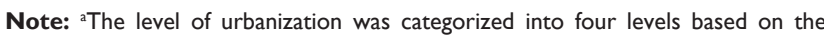
population density of the participants' area of residence, where "I" was most urbanized and "4" was least urbanized.

Abbreviations: $\mathrm{CHF}$, congestive heart failure; COPD, chronic obstructive pulmonary disease; DM, diabetes mellitus; ESRD, end-stage renal disease; PAOD, peripheral arterial occlusive disease; SD, standard deviation. patient selection is illustrated in a flowchart (Figure 1). The mean age was 62 years, and $\sim 60 \%$ of the patients were older than 60 years. The population was predominantly male, accounting for $75 \%$ of patients. The prevalence of comorbidities, including hypertension, hyperlipidemia, stroke, PAOD, CHF, cancer, and ESRD, was higher in the COPD cohort.

\section{Incidence of AF in Asian COPD patients}

The incidence of AF was higher in COPD patients than in those without COPD (Table 2). Figure 2 shows the Kaplan-Meier estimates of first AF event in patients with and without COPD. The adjusted HR for AF among COPD patients was 2.23 with a $95 \%$ CI of $1.98-2.51$ compared to those without COPD. After age stratification, the incidence of AF was increased with advanced age, with incidence rates of 0.84 and 5.23 per 100,000 person-years in patients between 40 and 49 years and in those aged $>70$ years, respectively.

Patients with COPD and other comorbidities, including hypertension, DM, hyperlipidemia, stroke, PAOD, CHF, and cancer, had a higher incidence of AF than patients with the same comorbidities but without COPD. However, a higher incidence of AF was not observed in patients with COPD and ESRD compared to those with ESRD but without COPD.

\section{Subgroup analysis}

Table 3 shows that the incidence of AF was higher in 40- to 49-year-old male COPD patients than in male patients without COPD, with an adjusted HR of $4.54(95 \% \mathrm{CI}=2.22-9.31)$. Among female COPD patents, the incidence of AF was highest in the 50-59-year age group, with an adjusted HR of $3.94(95 \%$ CI $=1.91-8.13)$.

Table 4 shows that after multivariable analysis, COPD patients had an HR of 2.23 (95\% CI $=1.98-2.51)$ for AF. Aging is associated with the incidence of AF. Compared to the 40- to 49-year-old age group, the incidence of AF was much higher in the group aged $>70$ years, with an HR of $7.50(95 \% \mathrm{CI}=5.64-9.96)$. Male COPD patients had a higher incidence of AF than female COPD patients.

After multiple analyses, patients with hypertension and CHF were found to have significantly higher incidences of AF than those without these conditions, with an HR of $1.43(95 \% \mathrm{CI}=1.26-1.62)$ and $2.36(95 \% \mathrm{CI}=1.81-3.08)$, respectively.

\section{Discussion \\ Main findings}

We used a nationwide database for Taiwan to investigate the incidence of new-onset AF in Asian COPD patients. 


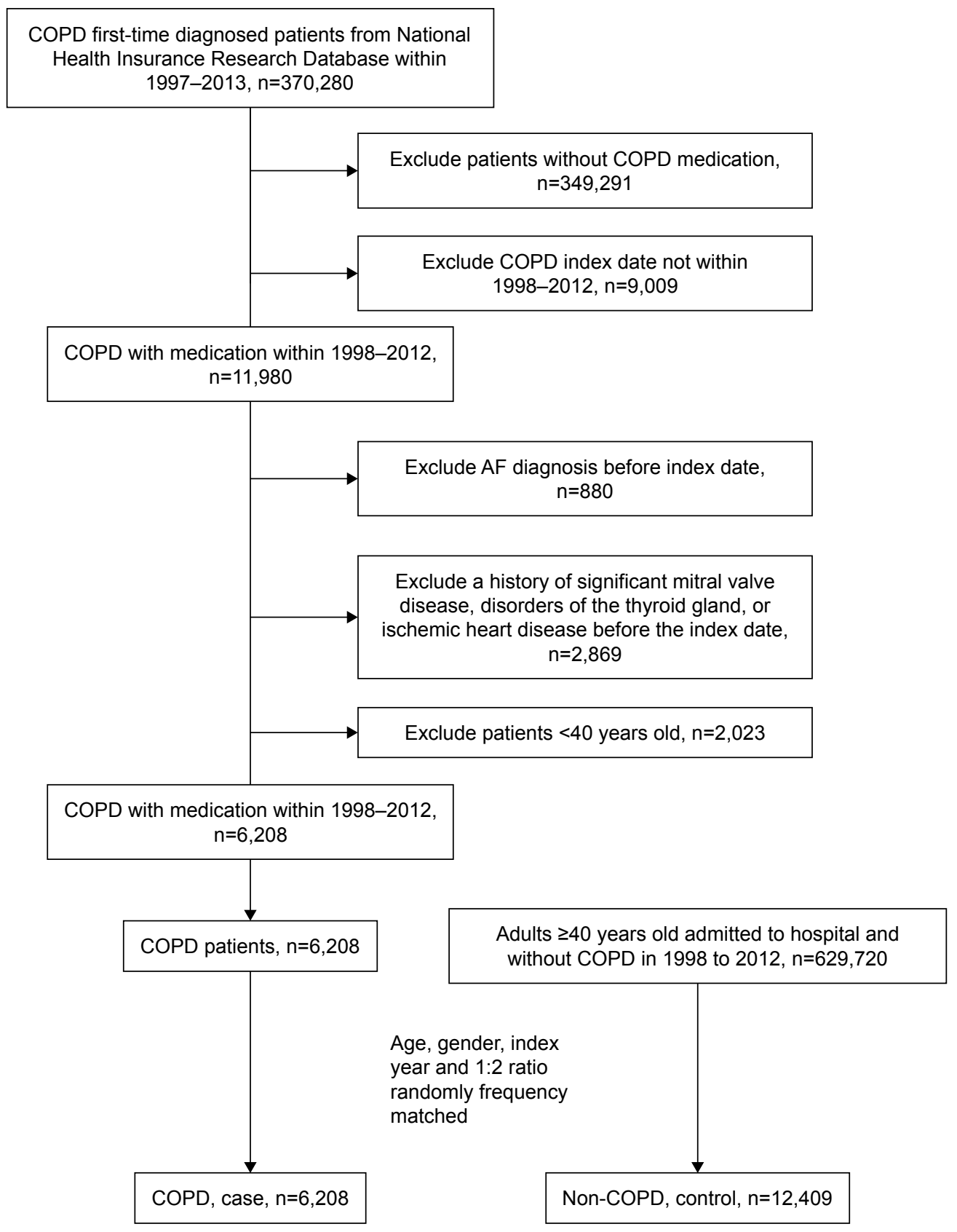

Figure I A flow chart that identifies the number of patients and study design.

Abbreviations: AF, atrial fibrillation; COPD, chronic obstructive pulmonary disease.

Our study produced several findings. First, COPD was associated with the risk of AF, with an adjusted HR of 2.23 compared to patients without COPD. Second, the risk of AF increased with older age in patients with or without COPD. Compared to male patients without COPD, male patients with COPD had a 4.5-fold higher risk of AF among the 40- to 49-year-old age group. Third, among patients with COPD, two comorbidities, hypertension and CHF, were associated with significantly higher risks of AF in our study, with HRs of 1.43 and 2.36, respectively. Fourth, for COPD patients aged $>70$ years, the risk of $\mathrm{AF}$ was 7.5 times greater than for those aged $40-49$ years.

\section{Lung function and $A F$}

In the ARIC study, ${ }^{12}$ middle-aged COPD patients with a mean age of 54 years, which is less than the mean age of our study population, were surveyed. New-onset AF was compared between different pulmonary function groups, which showed that lower pulmonary function was associated with a higher incidence of AF after adjusting for confounders. Buch et al ${ }^{15}$ 
Table 2 Incidence of AF in patients with and without COPD

\begin{tabular}{|c|c|c|c|c|c|c|c|c|c|c|}
\hline \multirow{2}{*}{$\begin{array}{l}\text { Characteristics } \\
\text { and } \\
\text { comorbidities }\end{array}$} & \multicolumn{3}{|c|}{ Non-COPD $(n=12,409)$} & \multicolumn{3}{|c|}{ COPD $(n=6,208)$} & \multirow{2}{*}{$\begin{array}{l}\text { Crude HR } \\
(95 \% \mathrm{CI})\end{array}$} & \multirow[t]{2}{*}{$P$-value } & \multirow{2}{*}{$\begin{array}{l}\text { Adjusted HR } \\
(95 \% \mathrm{Cl})\end{array}$} & \multirow[t]{2}{*}{$P$-value } \\
\hline & Event & PY & $\begin{array}{l}\text { Incidence } \\
\text { rate }\end{array}$ & Event & PY & $\begin{array}{l}\text { Incidence } \\
\text { rate }\end{array}$ & & & & \\
\hline$\overline{\text { AF }}$ & 543 & $45,944,356$ & 1.18 & 609 & $21,776,549$ & 2.80 & $2.39(2.13-2.68)$ & $<0.001$ & $2.23(\mathrm{I} .98-2.5 \mathrm{I})$ & $<0.001$ \\
\hline \multicolumn{11}{|c|}{ Age stratification, years } \\
\hline $40-49$ & 18 & $8,856,168$ & 0.20 & 36 & $4,310,183$ & 0.84 & $4.16(2.36-7.33)$ & $<0.00 \mathrm{I}$ & $3.92(2.21-6.95)$ & $<0.001$ \\
\hline $50-59$ & 62 & $11,286,102$ & 0.55 & 96 & $5,328,442$ & 1.80 & $3.34(2.42-4.59)$ & $<0.00$ I & $3.03(2.19-4.20)$ & $<0.001$ \\
\hline $60-69$ & 177 & $|4,63|, 907$ & 1.21 & 200 & $6,838,304$ & 2.92 & $2.46(2.0 \mathrm{I}-3.0 \mathrm{I})$ & $<0.001$ & $2.3(1.87-2.83)$ & $<0.001$ \\
\hline$\geq 70$ & 286 & $11,170,179$ & 2.56 & 277 & $5,299,620$ & 5.23 & $2.06(1.74-2.43)$ & $<0.001$ & $1.90(1.61-2.25)$ & $<0.001$ \\
\hline \multicolumn{11}{|l|}{ Gender } \\
\hline Male & 430 & $33,572,828$ & 1.28 & 476 & $|6,007,64|$ & 2.97 & $2.34(2.06-2.67)$ & $<0.00 \mathrm{I}$ & $2.19(1.92-2.5 \mathrm{I})$ & $<0.001$ \\
\hline Female & 113 & $|2,37|, 528$ & 0.91 & 133 & $5,768,908$ & 2.31 & $2.54(1.97-3.26)$ & $<0.00 \mathrm{I}$ & $2.34(1.81-3.02)$ & $<0.001$ \\
\hline \multicolumn{11}{|l|}{ Comorbidities } \\
\hline \multicolumn{11}{|l|}{ Hypertension } \\
\hline Yes & 208 & $11,769,866$ & 1.77 & 301 & $7,056,015$ & 4.27 & $2.44(2.05-2.92)$ & $<0.00 \mathrm{I}$ & $2.45(2.05-2.93)$ & $<0.001$ \\
\hline No & 335 & $34,174,490$ & 0.98 & 308 & $14,720,534$ & 2.09 & $2.15(1.84-2.51)$ & $<0.001$ & $2.03(1.74-2.38)$ & $<0.001$ \\
\hline \multicolumn{11}{|l|}{ DM } \\
\hline Yes & 51 & $3,58|, 03|$ & 1.42 & 51 & I,779, I। & 2.87 & $2.01(1.37-2.97)$ & $<0.001$ & $2.11(1.42-3.13)$ & $<0.001$ \\
\hline No & 492 & $42,363,325$ & 1.16 & 558 & $19,997,437$ & 2.79 & $2.42(2.15-2.74)$ & $<0.001$ & $2.23(1.97-2.53)$ & $<0.001$ \\
\hline \multicolumn{11}{|l|}{ Hyperlipidemia } \\
\hline Yes & 45 & $3,703,733$ & 1.21 & 62 & $2,217,259$ & 2.80 & $2.29(1.56-3.36)$ & $<0.001$ & $2.46(1.67-3.64)$ & $<0.001$ \\
\hline No & 498 & $42,240,623$ & 1.18 & 547 & $19,559,290$ & 2.80 & $2.39(2.12-2.70)$ & $<0.001$ & $2.20(1.95-2.50)$ & $<0.001$ \\
\hline \multicolumn{11}{|l|}{ Stroke } \\
\hline Yes & 57 & $2,606,648$ & 2.19 & 90 & $2,051,385$ & 4.39 & $2.00(1.43-2.79)$ & $<0.001$ & $2.07(1.48-2.90)$ & $<0.001$ \\
\hline No & 486 & $43,337,708$ & 1.12 & 519 & $19,725,164$ & 2.63 & $2.37(2.09-2.68)$ & $<0.001$ & $2.24(1.98-2.54)$ & $<0.001$ \\
\hline \multicolumn{11}{|l|}{ PAOD } \\
\hline Yes & 7 & 453,007 & 1.55 & 15 & 301,015 & 4.98 & $3.13(1.28-7.68)$ & 0.013 & $2.61(1.02-6.67)$ & 0.045 \\
\hline No & 536 & $45,491,349$ & 1.18 & 594 & $21,475,534$ & 2.77 & $2.37(2.106-2.66)$ & $<0.001$ & $2.21(1.97-2.49)$ & $<0.001$ \\
\hline \multicolumn{11}{|l|}{$\mathrm{CHF}$} \\
\hline Yes & 10 & 250,933 & 3.99 & 51 & 626,551 & 8.14 & $2.00(1.01-3.94)$ & 0.046 & $2.03(1.01-4.08)$ & 0.048 \\
\hline No & 533 & $45,693,423$ & 1.17 & 558 & $21,149,998$ & 2.64 & $2.28(2.02-2.57)$ & $<0.00 \mathrm{I}$ & $2.23(I .98-2.5 I)$ & $<0.001$ \\
\hline \multicolumn{11}{|l|}{ Cancer } \\
\hline Yes & 30 & $2,618,936$ & 1.15 & 72 & I,785, I 30 & 4.03 & $3.59(2.34-5.50)$ & $<0.00 \mathrm{I}$ & $3.40(2.21-5.25)$ & $<0.001$ \\
\hline No & 513 & $43,325,420$ & 1.18 & 537 & $19,991,419$ & 2.69 & $2.29(2.03-2.58)$ & $<0.00 \mathrm{I}$ & $2.15(1.90-2.43)$ & $<0.001$ \\
\hline \multicolumn{11}{|l|}{ ESRD } \\
\hline Yes & 11 & 584,920 & 1.88 & 20 & $44 I, 605$ & 4.53 & $2.47(1.183-5.17)$ & 0.016 & $2.01(0.91-4.44)$ & 0.085 \\
\hline No & 532 & $45,359,436$ & 1.17 & 589 & $21,334,944$ & 2.76 & $2.37(2.11-2.67)$ & $<0.001$ & $2.23(\mathrm{I} .98-2.5 \mathrm{I})$ & $<0.001$ \\
\hline
\end{tabular}

Abbreviations: AF, atrial fibrillation; CHF, congestive heart failure; $\mathrm{Cl}$, confidence interval; COPD, chronic obstructive pulmonary disease; DM, diabetes mellitus; ESRD, end-stage renal disease; HR, hazard ratio; PAOD, peripheral arterial occlusive disease; PY, per 100,000 person-years.

also concluded that lung function is an independent predictor of the incidence of AF.

These studies examined the relationship between pulmonary function and new-onset AF in Caucasian populations. Meanwhile, Shibata et a ${ }^{16}$ enrolled 2,917 participants aged 40 years or older from a community in Takahata, Japan, during health checks from 2004 to 2005 and concluded that impaired lung function was an independent risk factor for $\mathrm{AF}$ in the Japanese population. Other studies ${ }^{10,13,14,17}$ have also investigated the relationship between pulmonary function and AF, but these studies contained a small study population of Asian patients, and only a few of the studies focused on the prevalence of AF or compared the incidence of AF between
COPD patients with different lung functions. To the best of our knowledge, this is the first study to use a nationwide database of an Asian population to compare the incidence of AF in patients with and without COPD.

\section{$A F$ in COPD patients}

The adjusted HR was 2.23 for AF in COPD patients compared to patients without COPD. In a single-center study, Ganga et a $1^{18}$ used ICD-9-CM codes for analysis of patients $>65$ years of age without AF in 2006 and divided them into an obstructive sleep apnea group $(n=60)$, a COPD group ( $\mathrm{n}=416)$, and an overlap syndrome group $(\mathrm{n}=28)$. Their incidence rates of AF were $6 \%, 10 \%$, and $21 \%$, respectively, 


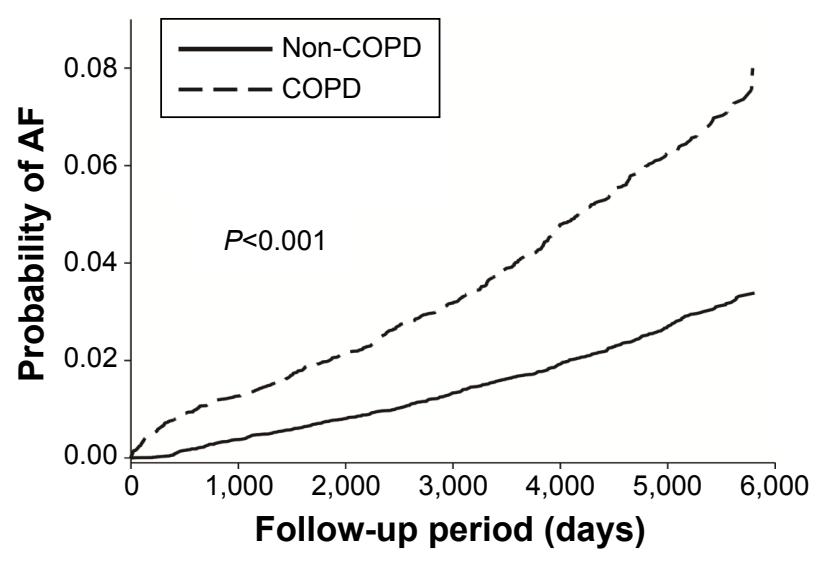

Figure 2 Kaplan-Meier estimates of first AF event in patients with and without COPD.

Abbreviations: AF, atrial fibrillation; COPD, chronic obstructive pulmonary disease.

but the HRs compared to the general population were not given. Kim et a $1{ }^{19}$ used data from a US commercial insurance plan to examine the incidence rate of hospitalization for $\mathrm{AF}$ in patients with rheumatoid arthritis. After adjusting for potential confounders of $\mathrm{AF}$, patients with rheumatoid arthritis did not have an increased risk of AF (HR 1.1, 95\% CI $=0.9-1.4$ ) compared to patients without rheumatoid arthritis. Liao et a ${ }^{20}$ used the same database and showed that patients with ESRD had a higher risk of AF (HR 2.26, 95\% CI $=2.16-2.37$ ) than patients without ESRD. The risk of AF in patients with COPD was similar to that of patients with ESRD.

\section{Effect of comorbidities on the incidence of $A F$ in Asian COPD patients}

In the study by Ganga et al, ${ }^{18} \mathrm{CHF}$, chronic kidney disease, and hypertension were risk factors for $\mathrm{AF}$ in the geriatric population. In our study, we demonstrated that CHF and hypertension were also significantly associated with newonset $\mathrm{AF}$ in the COPD population. Although ESRD was identified as a risk factor for $\mathrm{AF}$ in a previous study, ${ }^{20}$ in our study, ESRD was not a risk factor for AF in the COPD population. This result may have occurred because the number of ESRD patients with COPD was limited.

\section{Mechanism of AF in COPD}

There are many mechanisms of AF in COPD. The first mechanism involves inflammation. COPD is a systemic inflammatory disease, and serum C-reactive protein (CRP) levels are significantly higher in these patients than in healthy controls; CRP is also associated with age, lung function, oxygen saturation, dyspnea scales, and the Body-Mass Index, Airflow Obstruction, Dyspnea, and Exercise Capacity index. ${ }^{21}$ CRP elevation was observed in patients with AF. Although the reason for CRP elevation was not clear, the high CRP reflects an inflammatory state in coronary endothelial cells, which results in thromboembolic risk. ${ }^{22}$ The second mechanism involves medication. COPD patients are prescribed respiratory drugs, including short- or long-acting

Table 3 Incidence and hazard ratio of AF for patients with COPD compared to those without COPD, where gender and comorbidities are stratified by age groups (years)

\begin{tabular}{|c|c|c|c|c|c|c|c|c|c|c|}
\hline \multirow[t]{2}{*}{ Variables } & \multicolumn{3}{|c|}{ Non-COPD $(n=12,409)$} & \multicolumn{3}{|c|}{ COPD $(n=6,208)$} & \multirow{2}{*}{$\begin{array}{l}\text { Crude HR } \\
(95 \% \mathrm{CI})\end{array}$} & \multirow[t]{2}{*}{$P$-value } & \multirow{2}{*}{$\begin{array}{l}\text { Adjusted } \mathbf{H R}^{\mathrm{a}} \\
(95 \% \mathrm{Cl})\end{array}$} & \multirow[t]{2}{*}{$P$-value } \\
\hline & Event & PY & $\begin{array}{l}\text { Incidence } \\
\text { rate }\end{array}$ & Event & PY & $\begin{array}{l}\text { Incidence } \\
\text { rate }\end{array}$ & & & & \\
\hline \multicolumn{11}{|l|}{ Male } \\
\hline $40-49$ & 11 & $5,780,311$ & 0.19 & 26 & $2,821,7 \mid 3$ & 0.92 & $4.97(2.45-10.08)$ & $<0.00$ I & $4.54(2.22-9.31)$ & $<0.001$ \\
\hline $50-59$ & 50 & $8,101,943$ & 0.62 & 72 & $3,840,27$ I & 1.87 & $3.13(2.18-4.49)$ & $<0.001$ & $2.88(2.00-4.16)$ & $<0.001$ \\
\hline $60-69$ & 130 & $|1| 4 \mid, 529$, & 1.17 & 157 & $5,225,353$ & 3.00 & $2.61(2.07-3.30)$ & $<0.00$ I & $2.44(1.93-3.10)$ & $<0.001$ \\
\hline$\geq 70$ & 239 & $8,549,045$ & 2.80 & 221 & $4,120,304$ & 5.36 & $1.93(1.61-2.32)$ & $<0.001$ & $1.80(1.49-2.17)$ & $<0.001$ \\
\hline \multicolumn{11}{|l|}{ Female } \\
\hline $40-49$ & 7 & $3,075,857$ & 0.23 & 10 & $\mathrm{I}, 488,470$ & 0.67 & $2.92(1.11-7.66)$ & 0.03 & $2.83(1.06-7.58)$ & 0.038 \\
\hline $50-59$ & 12 & $3,184,159$ & 0.38 & 24 & $|, 488| 7 \mid$, & 1.61 & $4.23(2.11-8.45)$ & $<0.001$ & $3.94(1.91-8.13)$ & $<0.001$ \\
\hline $60-69$ & 47 & $3,490,378$ & 1.35 & 43 & $|, 612,95|$ & 2.67 & $2.03(1.34-3.06)$ & 0.001 & $1.89(1.24-2.87)$ & 0.003 \\
\hline$\geq 70$ & 47 & $2,621,134$ & 1.79 & 56 & $I, \mid 79,316$ & 4.75 & $2.67(1.8 I-3.94)$ & $<0.001$ & $2.34(1.57-3.50)$ & $<0.001$ \\
\hline \multicolumn{11}{|c|}{ Comorbidities } \\
\hline $40-49$ & 4 & $\mathrm{I}, 728,435$ & 0.23 & 12 & $\mathrm{I}, 304,450$ & 0.92 & $3.89(1.25-12.06)$ & 0.019 & $3.50(1.11-10.99)$ & 0.032 \\
\hline $50-59$ & 29 & $3,589,150$ & 0.81 & 61 & $2,295,463$ & 2.66 & $3.37(2.16-5.25)$ & $<0.001$ & $3.27(2.08-5.14)$ & $<0.001$ \\
\hline $60-69$ & 83 & $6,154,868$ & 1.35 & 134 & $3,640,494$ & 3.68 & $2.79(2.12-3.67)$ & $<0.001$ & $2.63(1.99-3.48)$ & $<0.00$ I \\
\hline$\geq 70$ & 169 & $5,675,950$ & 2.98 & 191 & $3,223,472$ & 5.93 & $2(1.63-2.46)$ & $<0.001$ & $1.85(1.50-2.29)$ & $<0.001$ \\
\hline
\end{tabular}

Note: ${ }^{A}$ Adjusted factor: age groups (40-49, 50-59, 60-69, and >70 years), urbanization (levels I-4), gender, and comorbidities (hypertension, DM, hyperlipidemia, ESRD, CHF, stroke, PAOD, and malignancy).

Abbreviations: AF, atrial fibrillation; $\mathrm{CHF}$, congestive heart failure; $\mathrm{Cl}$, confidence interval; COPD, chronic obstructive pulmonary disease; DM, diabetes mellitus; ESRD, end-stage renal disease; HR, hazard ratio; PAOD, peripheral arterial occlusive disease; PY, per 100,000 person-years. 
Table 4 Predictors of new-onset AF in COPD patients

\begin{tabular}{|c|c|c|c|c|}
\hline \multirow[t]{2}{*}{ Variables } & \multicolumn{2}{|l|}{ Univariate analysis } & \multicolumn{2}{|c|}{ Multivariable analysis $^{a}$} \\
\hline & HR (95\% Cl) & $P$-value & HR (95\% Cl) & $P$-value \\
\hline COPD & $2.386(2.125-2.679)$ & $<0.001$ & $2.23 \mathrm{I}(\mathrm{I} .984-2.5 \mathrm{I})$ & $<0.001$ \\
\hline \multicolumn{5}{|c|}{ Age stratification, years } \\
\hline $40-49$ & 1.000 & & 1.000 & \\
\hline $50-59$ & $2.345(1.722-3.194)$ & $<0.001$ & $2.216(1.625-3.02)$ & $<0.001$ \\
\hline $60-69$ & $4.337(3.26-5.768)$ & $<0.001$ & $3.855(2.89-5.14 I)$ & $<0.001$ \\
\hline$\geq 70$ & $8.9 \mid 8$ (6.742-1।.797) & $<0.001$ & $7.496(5.64 I-9.96 I)$ & $<0.001$ \\
\hline \multicolumn{5}{|l|}{ Gender } \\
\hline Male & 1.377 (1.196-I.586) & $<0.001$ & $1.238(1.074-1.426)$ & 0.003 \\
\hline Female & 1.000 & & 1.000 & \\
\hline \multicolumn{5}{|l|}{ Urbanization } \\
\hline I (highest) & 1.000 & & 1.000 & \\
\hline 2 & 1.091 (0.94-I.267) & 0.251 & $1.056(0.909-1.226)$ & 0.476 \\
\hline 3 & I.3 (I.087-I.554) & 0.004 & $1.120(0.936-1.340)$ & 0.216 \\
\hline 4 (lowest) & $1.236(1.018-1.5)$ & 0.032 & $1.054(0.868-1.280)$ & 0.595 \\
\hline \multicolumn{5}{|l|}{ Comorbidities } \\
\hline Hypertension & $2.084(I .855-2.34 I)$ & $<0.001$ & $1.43 \mid(\mid .263-1.622)$ & $<0.001$ \\
\hline DM & $1.116(0.911-1.368)$ & 0.289 & $0.848(0.689-1.045)$ & 0.121 \\
\hline Hyperlipidemia & I. 109 (0.909-I.354) & 0.307 & 0.906 (0.739-I.I I0) & 0.339 \\
\hline Stroke & 2.006 (1.687-2.385) & $<0.001$ & I.I43 (0.955-I.369) & 0.145 \\
\hline PAOD & $1.779(1.166-2.7 \mid 3)$ & 0.007 & I.I0I (0.7I8-I.687) & 0.659 \\
\hline Heart failure & $4.579(3.535-5.933)$ & $<0.001$ & $2.356(1.806-3.075)$ & $<0.001$ \\
\hline Cancer & $1.379(1.125-1.689)$ & 0.002 & I.I $50(0.937-1.41 \mathrm{I})$ & 0.180 \\
\hline ESRD & $1.884(1.318-2.693)$ & 0.001 & I.I44 (0.795-I.646) & 0.469 \\
\hline
\end{tabular}

Note: aAjusted factor: age groups (40-49, 50-59, 60-69, and >70 years), urbanization (levels I-4), gender, and comorbidities (hypertension, DM, hyperlipidemia, ESRD, CHF, stroke, PAOD, and malignancy).

Abbreviations: AF, atrial fibrillation; CHF, congestive heart failure; $\mathrm{Cl}$, confidence interval; COPD, chronic obstructive pulmonary disease; DM, diabetes mellitus; ESRD, end-stage renal disease; HR, hazard ratio; PAOD, peripheral arterial occlusive disease.

$\beta$-agonists, anticholinergic drugs, and methylxanthine drugs, such as theophylline and aminophylline. $\beta$-agonists activate $\beta$-receptors and adenylate cyclase, leading to the activation of cyclic adenosine monophosphate and protein kinase A, which phosphorylates target proteins and leads to a contraction of myocytes. These chronotropic and depolarization effects lead to arrhythmogenicity. ${ }^{8}$ Anticholinergic medications suppress parasympathetic tone and increase the incidence of tachyarrhythmias. ${ }^{23}$ Methylxanthine drugs increase the excretion of potassium and magnesium through the urine and may cause the depolarizing effects that underlie arrhythmogenesis. ${ }^{24}$ Other factors that induce AF in the COPD population include older age, hypoxia, smoking, and cardiovascular disease. ${ }^{16}$

\section{Limitations}

There are several limitations in our study. First, no data regarding pulmonary function tests, laboratory tests, body mass index, dyspnea scales and smoking history were included in our database. The association of AF and COPD severity cannot be identified in our study. Previous studies, such as the Takahata Study, ${ }^{16}$ have suggested a relationship between lung function and AF. Our study aimed to define the incidence of $\mathrm{AF}$ in the COPD population regardless of its severity. All COPD patients in our study received bronchodilator medications. Our results have generalizability to COPD patients treated by bronchodilators but may not reflect patients with mild COPD without treatment. Another possible limitation of our study was misdiagnosis. The diagnoses of COPD were dependent on ICD codes used in the database. However, we believe that this dataset is comprehensive, and the large number of patients may compensate for these limitations. Efforts have been made to ensure the accuracy of the diagnoses by performing random chart reviews and patient interviews by the National Health Insurance Bureau.

\section{Conclusion}

Despite these limitations, our study has demonstrated that after adjusting for possible confounding factors related to $\mathrm{AF}, \mathrm{COPD}$ patients had a higher risk of AF than did patients without COPD among the Asian population. Among COPD patients, hypertension and CHF were identified as independent risk factors for new-onset AF. The results also suggest 
that physicians need to increase monitoring and early intervention for COPD patients to treat AF.

\section{Acknowledgments}

This work was supported by a grant from the Chi Mei Medical Center and Kaohsiung Medical University Research Foundation (106CM-KMU-10).

\section{Disclosure}

The authors report no conflicts of interest in this work.

\section{References}

1. January CT, Wann LS, Alpert JS, et al. 2014 AHA/ACC/HRS guideline for the management of patients with atrial fibrillation: a report of the American College of Cardiology/American Heart Association Task Force on Practice Guidelines and the Heart Rhythm Society. J Am Coll Cardiol. 2014;64(21):e1-e76.

2. Wolf PA, Abbott RD, Kannel WB. Atrial fibrillation as an independent risk factor for stroke: the Framingham Study. Stroke. 1991;22(8): 983-988.

3. Magnani JW, Rienstra M, Lin H, et al. Atrial fibrillation: current knowledge and future directions in epidemiology and genomics. Circulation. 2011;124(18):1982-1993.

4. Rienstra M, McManus DD, Benjamin EJ. Novel risk factors for atrial fibrillation. Useful for risk prediction and clinical decision making? Circulation. 2012;125(20):e941-e946.

5. Kinoshita M, Herges RM, Hodge DO, et al. Role of smoking in the recurrence of atrial arrhythmias after cardioversion. Am J Cardiol. 2009; 104(5):678-682.

6. Korantzopoulos P, Kolettis TM, Galaris D, Goudevenos JA. The role of oxidative stress in the pathogenesis and perpetuation of atrial fibrillation. Int $J$ Cardiol. 2007;115(2):135-143.

7. Ogi $\mathrm{H}$, Nakano $\mathrm{Y}$, Niida $\mathrm{S}$, et al. Is structural remodeling of fibrillated atria the consequence of tissue hypoxia? Circ J. 2010;74(9):1815-1821.

8. Salpeter SR, Ormiston TM, Salpeter EE. Cardiovascular effects of betaagonists in patients with asthma and COPD: a meta-analysis. Chest. 2004;125(6):2309-2321.

9. Christiansen CF, Christensen S, Mehnert F, Cummings SR, Chapurlat RD, Sørensen HT. Glucocorticoid use and risk of atrial fibrillation or flutter: a population-based, case-control study. Arch Intern Med. 2009;169(18):1677-1683.
10. Konecny T, Park JY, Somers KR, et al. Relation of chronic obstructive pulmonary disease to atrial and ventricular arrhythmias. Am J Cardiol. 2014;114(2):272-277.

11. Méndez-Bailón M, Lopez-de-Andrés A, de Miguel-Diez J, et al. Chronic obstructive pulmonary disease predicts higher incidence and in hospital mortality for atrial fibrillation. An observational study using hospital discharge data in Spain (2004-2013). Int J Cardiol. 2017;236:209-215.

12. Li J, Agarwal SK, Alonso A, et al. Airflow obstruction, lung function, and incidence of atrial fibrillation. The Atherosclerosis Risk in Communities (ARIC) Study. Circulation. 2014;129(9):971-980.

13. Johnson LS, Juhlin T, Engström G, Nilsson PM. Reduced forced expiratory volume is associated with increased incidence of atrial fibrillation: the Malmö Preventive Project. Europace. 2014;16(2):182-188.

14. Chahal H, Heckbert SR, Barr RG, et al. Ability of reduced lung function to predict development of atrial fibrillation in persons aged 45 to 84 years (from the Multi-Ethnic Study of Atherosclerosis-Lung Study). Am J Cardiol. 2015;115(12):1700-1704.

15. Buch P, Friberg J, Scharling H, Lange P, Prescott E. Reduced lung function and risk of atrial fibrillation in The Copenhagen City Heart Study. Eur Respir J. 2003;21(6):1012-1016.

16. Shibata $Y$, Watanabe $T$, Osaka $D$, et al. Impairment of pulmonary function is an independent risk factor for atrial fibrillation: the Takahata Study. Int J Med Sci. 2011;8(7):514-522.

17. Terzano C, Romani S, Conti V, Paone G, Oriolo F, Vitarelli A. Atrial fibrillation in the acute, hypercapnic exacerbations of COPD. Eur Rev Med Pharmacol Sci. 2014;18(19):2908-2917.

18. Ganga HV, Nair SU, Puppala VK, Miller WL. Risk of new-onset atrial fibrillation in elderly patients with the overlap syndrome: a retrospective cohort study. J Geriatr Cardiol. 2013;10(2):129-134.

19. Kim SC, Liu J, Solomon DH. The risk of atrial fibrillation in patients with rheumatoid arthritis. Ann Rheum Dis. 2014;73(6):1091-1095.

20. Liao JN, Chao TF, Liu CJ, et al. Incidence and risk factors for new-onset atrial fibrillation among patients with end-stage renal disease undergoing renal replacement therapy. Kidney Int. 2015;87(6):1209-1215.

21. Aksu F, Capan N, Aksu K, et al. C-reactive protein levels are raised in stable chronic obstructive pulmonary disease patients independent of smoking behavior and biomass exposure. J Thorac Dis. 2013;5(4):414-421.

22. Chung MK, Martin DO, Sprecher D, et al. C-reactive protein elevation in patients with atrial arrhythmias: inflammatory mechanisms and persistence of atrial fibrillation. Circulation. 2001;104(24):2886-2891.

23. van Vlymen JM, Parlow JL. The effects of reversal of neuromuscular blockade on autonomic control in the perioperative period. Anesth Analg. 1997;84(1):148-154.

24. Wood-Baker R, Cochrane B, Naughton MT. Cardiovascular mortality and morbidity in chronic obstructive pulmonary disease: the impact of bronchodilator treatment. Intern Med J. 2010;40(2):94-101.
International Journal of COPD

\section{Publish your work in this journal}

The International Journal of COPD is an international, peer-reviewed journal of therapeutics and pharmacology focusing on concise rapid reporting of clinical studies and reviews in COPD. Special focus is given to the pathophysiological processes underlying the disease, intervention programs, patient focused education, and self management protocols.

\section{Dovepress}

This journal is indexed on PubMed Central, MedLine and CAS. The manuscript management system is completely online and includes a very quick and fair peer-review system, which is all easy to use. Visit $\mathrm{http}: / / \mathrm{www}$.dovepress.com/testimonials.php to read real quotes from published authors. 